\title{
Problem-Solving Skills of High School Students Exercising Regularly in Sport Teams
}

Authors' contribution:

A) conception and design of the study

B) acquisition of data

C) analysis and interpretation of data

D) manuscript preparation

E) obtaining funding

\author{
Fatih Senduran $^{\mathrm{A}-\mathrm{E}}$, Tayfun Amman ${ }^{\mathrm{A}, \mathrm{D}}$
}

Marmara University, Turkey

\section{KEYWORDS}

\begin{abstract}
In this article, the effect of regular sport activities on the problem-solving approaches performed by high school students when they encountered said problem was analyzed. Six hundred male high school students participated in the study ( $\mathrm{M}_{\text {age }}=15.45$ years, age range: $14-17$ years). The Problem-Solving Inventory (PSI) was used to evaluate students' problem-solving solutions. Student-athletes were selected from the students who took charge in school teams, exercised for 6 days a week, provided that this exercise did not exceed $1 \mathrm{~h} 30 \mathrm{~min}$, and who also participated in competitions. Mann-Whitney U test, which is nonparametrictest, was used to examine two samples (athlete, \& non-athlete) and Kruskal-Wallis one-way analysis was used to make intergroup (branches of sport) examinations. According to the findings that were obtained, a significant difference was found among selfconfident approach values of athlete and non-athlete students ( $U=45.0, p=0.008)$. A significant difference was observed among assessor approach values of athlete and non-athlete students $(U=46.2, p=0.033)$. The students who did sports regularly were more self-confident than those who did not do sports regularly and were of the same age when they encountered a problem, and student-athletes evaluated the phase of solving the problem and results that they obtained more carefully than those who did not do sport regularly and were of the same age. Student-athletes believed that they would solve the problem that they encountered. Further, student athletes preferred using a systematic method while solving a problem and making a decision more often than those who were not athletes and were of the same age.

problem solving, sport, exercising, school, education
\end{abstract}

\section{Introduction}

Parents, educators, physicians, coaches, and adolescents acknowledge and promote the health benefits of regular physical activity in shaping the lives of young people (Pateli, \& Greydanus, 2010). The schools are some of the most important institutions in which regular physical activities are carried out. The schools contribute to the behavior and personal development of students with different programs and systematic activities and prepare the students against the problems that they will encounter during their lifetimes. Supporters of having youth adopt a competitive attitude toward their sport participation confirm their actions 
by saying that competition is a beneficial tool to teach these youth how to make physical activity a part of a lifelong strategy; to continue to be physical fit; and also to teach them many important things on the participation in life, how to win, and even more important, how to lose but maintain a winning behavior (Pateli, \& Greydanus, 2010). In this article, the effect of regular sport activities on the problemsolving approaches performed by high school students when they encountered said problem was analyzed.

The futures of societies are shaped by new solutions that young generations raised by them develop against problems that they encounter. Schools take on an important task for raising young generations and providing that they gain problem-solving skills. Problem-solving skills can be developed with systematic work from primary school (Ulucinar, 2011). D'Zurilla, A.M. Nezu, and C.M. Nezu (2007) emphasized that we encounter numerous problems against which we should struggle during our life and that the most important thing is that we should know how to struggle with these problems for our mental and physical health. The problems are obstacles that oppose the current strengths gathered by an individual to achieve demanded goal and that also include known or indefinite subjects (Bingham, 1958). D'Zurilla, and Nezu (1990) stated that problem solving is a cognitive, affective, and behavioral process that an individual develops and produces to be able to find the way for coping with problems effectively that he/ she encounters in his/ her daily life. This process looks for a way to get rid of tension via meeting the requirements or decreasing obstacles and to provide that the organism has an internal balance. Problem solving is a skill that should be learned and obtained. Since it is multidirectional, it combines intelligence, emotions, desire, and action in itself with creative (reflective) thinking (Bingham, 1958). Further, problem solving requires trying new strategies to obtain the result and eliminating those who are unsuccessful (Thornton, 1998). Those who can solve problems efficiently can adapt to life's difficulties individually. D'Zurilla et al. (2007) stated that efficient problem solving facilitates health and emotions getting better and self-esteem and self-confidence developing and that it increased quality of life. Efficient problem-solving process is realized in five steps. These are, respectively, believing in solving problem and adapting to problem, defining the problem correctly and determining achievable targets, forming different alternatives to clear the hurdle, predicting how positive and negative results of alternatives and how maximum efficiency is obtained with the lowest cost, and lastly, creating a plan and trying it in real life. At the end of all these phases, if you are unhappy, it is necessary to go back to square one and start to look for the best solution (D'Zurilla et al., 2007).

Solving problems is one teaching method used by teachers and trainers. In the problem-solving method, coach-teacher sets problems for the learners to solve, which encourages learners to think about their sport and to be creative in their approach to problems (Woods, 2004). The most difficult skills being learned are skill types that require a child to apply an abstract rule (discipline, respect, patience, etc.) or analyze a situation and develop a strategy beforehand. We want children to learn these things in school (Thornton, 1998). Problem solving is one of abstract skill types. In the process from childhood to adulthood, games are one of the important tools for developing problem-solving skills. In the schools, physical education lessons, sport team studies, and game activities are performed systematically and in a planned way, and they include an important time frame in the period of training a student. The most important material in the game is solving the problem (Thornton, 1998). The students gain new experiences in physical education lessons and with sport team activities. The more children have new experiences, the richer information they gather, and they also discover new tools for problem solving (Thornton, 1998). Sport can only be deemed as being consistent with education, rather than as just a beneficial tool that provides its own internal values in the way of skills, standards, and excellences that are deemed as beneficial and followed in a moral manner for their own sake (Arnold, 1997). While children observe, listen to other people, and solve problems in a social pattern easily, they learn lots of things (Thornton, 1998). Success in problem solving depends on the fact that children make different inferences, can know and understand all aspects of said subject, and find and use new strategies (Thornton, 1998).

In the sporting arena, performers encounter many competitive demands and react in different ways (Mellalieu, Fletcher, \& Hanton, 2009). Exercise was defined by Biddle, Kenneth, and Boutcher (2002) 
as a subset of physical activity that is volitional, planned, structured, repetitive, and aimed at improvement or maintenance of an aspect of fitness or health. Athletes encounter many physical and mental difficulties during the period of preparing for competitions. Athletes improve different physical, technical, tactical, and psychological skills for handling difficult, monotonous training and stressful competition conditions. Different psychological strategies/interferences should be applied to develop psychological skills (Blumenstein, \& Orbach, 2012). Solutions that athletes developed against problems that they encountered and the mental struggle provide them different advantages, and they obtain both physical and mental experiences.

It is obvious that the place of exercise in reducing physical illness is well understood; there has also been increasing interest in exercise's contribution to lowering problems with mental illness (Biddle et al., 2002). Davis, Roscoe, Roscoe, and Bull (2005) stated that successful athletes have a more positive mental health profile than less successful athletes or the general population. Studies that have been carried out are evidence of a relationship between psychological well-being and regular exercise participation. Cox (1998) accepts that people who do sports have different personal characteristics such as being more independent, objective, and less anxious. Further, Cox (1998) stated that regular exercise not only improves cardiovascular fitness, but it is also believed that it has a beneficial effect on the psychological mood of mentally healthy individuals.

Participation in regular exercise is a determinant of a number of psychological variables such as positive affect and well-being (Hagger, \& Chatzisarantis, 2005). We become aware of the things happening around us during physical activity. Information is transmitted to and from the brain via the nervous system. There are two elements constituting this system: i) the brain and the spinal cord forming the central nervous system (CNS) together, and ii) the peripheral nervous system, which compiles the nerves connecting the spinal cord with all body parts, radiating from (the afferent system) the CNS (Davis et al., 2005). Cox (1998) emphasized that a high level of performance in any human activity requires a certain amount of concentration and attention, and athletes should develop a highly refined ability to focus and have characteristics of refocusing. High school students who exercise regularly use their concentration and focusing skills in each exercise and competition regularly.

The player of games such as the politician or business executive has to learn to cope with disappointment as well as with triumph without being unduly affected by either (Arnold, 1997). Athletes may be stressed for many reasons. Athletes are stressed because of the exercise program, difficulty, and homogenouslife conditions. However, the most important one is competition stress. Athletes have to manage competition stress regularly. Athletes use two types of techniques while they manage the stress: these techniques are somatic (relating to body) or cognitive (relating to the mind). Athletes usually use both these two techniques in the phase of controlling the problem (Woods, 2004). The athletes who continuously apply these techniques use similar management techniques for problems that they encounter in their daily life. Admired qualities such as loyalty, cooperation, courage, resolution, willpower, self-control, endurance, and determination are often mentioned as arising from a participation in games and sport (Arnold, 1997).

The concentration and attention characteristics that the athletes have and that they continuously develop and their focusing skill that help them concentrate on problem-solving phase when they encounter a problem can be evaluated. When considering studies that were carried out, it can be said that regular sport activities contribute to the mental and psychological health of athletes. In this study, the potential effect of regular physical activities on the problem-solving skills of high school students during the transitional period from adolescence and to adulthood was investigated. In parallel with studies that were carried out beforehand, it is expected that perception, comprehension, decision making, and problem-solving skills obtained thanks to regular exercise and participation in competitions will positively contribute to the problem-solving methods of students. 


\section{Method}

\section{Participants}

Six hundred high school students participated in the study ( $\mathrm{M}_{\mathrm{age}}=15.45$ years, age range: $14-17$ years). Student-athletes who do regular physical activity were selected from the students who continue to do exercises regularly in sport teams of the school and compete in national competitions $\left(\mathrm{N}_{\text {athlete }}=319\right)$. The students who took charge in sport teams exercised for six days a week, provided that this exercise did not exceed $1.5 \mathrm{~h}$. They regularly participated in league competitions required by their branches of sport. Non-athlete students were selected randomly from among the students who do not do sport regularly $\left(\mathrm{N}_{\text {non-athlete }}=321\right)$.

\section{Material and Procedure}

In the study, the "Personal Information Form" and "Problem-Solving Inventory (PSI)" were used to evaluate problem-solving skills. In the personal information form, the participants were required to reply to three personal information questions: their age, whether they are athlete or not, and their branch of sport. The Problem-Solving Inventory (PSI) was developed by Heppner and Petersen (1982) in the United States of America to analyze the main dimensions of the personal problem-solving period in real life and factors in this period. The Problem-Solving Inventory (PSI) was translated into Turkish by Sahin and Petersen (1993). Turkish data provide additional psychometric support for the PSI and improve the generalizability of some of the previous findings that are based on U.S. samples. The Problem-Solving Inventory (PSI) is a 32-item Likert-type tool and style for problem solving. The responses to the items range between 1) strongly agree to 6) strongly disagree. Example items include "When confronted with a problem, I generally do the first thing that comes to my mind for solving it" and "When faced with new situation, I have confidence that I can handle problem that may arise". Total score range is 32 to 198 (Karabulut, \& Kuru, 2009). PSI scores are related to a wide range of cognitive, affective, and behavioral activities thought to be important in the coping process and also to a number of indices of psychological well-being. Lower scores indicate that the person perceives himself/ herself as more confident in problem solving and having more personal control over his/ her problems and a tendency to approach problems (Ferah, 2000).

Turkish version of the problem-solving inventory consisted of six factors. These factors are precipitant approach, thinking approach, avoidant approach, assessor approach, self-confident approach, and planned approach. Reliability results (Cronbach's alpha $=0.88$ ) of the Turkish version of Problem-Solving Inventory were satisfactory. Confirmatory six-factor analyses have provided good support. The alpha coefficients for the six factors were 0.78, 0.76, 0.74, 0.69, 0.64, and 0.59, respectively (Şahin, \& Petersen, 1993). Eight hundred male high school students participated in the study. Participants who do not meet the control were removed from the study and assessment. As a result, six hundred male high school students participated to be evaluated in the study. Six main factors of the Problem-Solving Inventory are defined in brief.

1. Precipitant Approach: This approach includes attitudes and behaviors of an individual such as directing toward first solution while solving problems and acting accordingly; focusing on details more than adequate without touching on the main problem; not creating new and a great number of solutions to solve the problem; and not evaluating the success possibility of potential solution options, considering other factors apart from itself that may contribute to solution of the problem that the said individual encountered, approaching the problems very sentimentally and considering many ways of dealing.

2. Assessor Approach: This approach includes attitudes and behaviors of an individual such as comparing emerging results and results thought to have been incurred by the said individual to solve the problem after trying a definite way; thinking of all ways that he/she can use all together; and considering his/her emotions for a problem. 
3. Planned Approach: This approach includes attitudes and behaviors of an individual such as being able to solve problems even though they are not in the first step of the problems; making decisions about oneself; being able to take responsibility about the fact that whether one is pleased with them; not directing toward another subject without thinking about said problem and solving it when one encounters a problem; and believing that one can manage that plan when one makes a plan for solving a problem.

4. Thinking Approach: This approach includes attitudes and behaviors of an individual such as thinking of all current choices while solving a problem; making a decision; comparing the choices with each other; reviewing the results one by one; anticipating problems, advantages, and disadvantages that it may cause before applying a definite problem solution; firstly reviewing the problem when faced with a problem; defining the problem completely and clearly; gathering every kinds of information relating to that problem; and considering these things and the fact that emerging result does not generally meet with satisfaction after applying a decision.

5. Avoidant Approach: This approach includes attitudes and behaviors of an individual such as decreased ability to cope with that problem when the first effort fails while solving the problem; if solution methods that were applied are ineffective, researching why they were not efficient; not thinking about what the problem that one encountered is and how one needs to gather information to define the said problem completely; and avoiding thinking on the factors positively or negatively affecting solution of the problem after solving said problem.

6. Self-Confident Approach: This approach defines new and difficult problems that the situation will bring when a time is given to an individual and that individual encounters new situations; competence in being able to solve his/ her problems generally in an efficient and creative way; and approaching his/ her problems in parallel with this reliance. This approach also includes an individual following a systematic method while solving his/ her problem, comparing solution methods, and making decisions. It is also accepted that this approach reflects self-reliance of the individual while solving his/ her problems, skill for being able to solve the problems, his/ her belief, and the fact that he/ she can make decisions about him/ herself and is pleased with these decisions.

\section{Procedure}

For this study, 813 students of the same school participated. The school where the study was carried out was a boarding school, and the same daily working program was being applied to everyone. In other words, it was planned when the students would get up in the morning, eat, relax, and sleep at night. The students were free to participate in the study. The students who did not want to reply to the inventory did not answer it. Of the participants, 213 students, who made mistakes at the end of the answering period of the inventory, who did not comply with reliability tolerances of the scale, and who did not want to be included into the study, were left out of the assessment for the reliability and validity of the study. In total, 600 male students formed the basis of the research. Student-athletes were selected from the students who took charge in school teams, exercised for six days in a week (provided that this exercise did not exceed $1 \mathrm{~h} 30 \mathrm{~min}$ ) and who also participated in competitions. The students answered the inventory in a free environment. The identity information of students was not required so that they would be comfortable during research and give answers more freely.

\section{Data analysis}

The data were displayed visually for outliers, and these data were checked for normality. Having calculated from the scale, total score and subscale scores that belong to normal distribution were checked with K-S test and the uniformity of variances was checked with Levene's test. The Mann-Whitney U test, which is non-parametrictest, was used to examine the two samples (athlete, \& non-athlete), and KruskalWallis one-way analysis was used to make intergroup (branches of sport) examinations. Descriptive statistics 
were also calculated on all study variables. A p-value of less than 0.05 was considered statistically significant.

\section{Results}

The Problem-Solving Inventory values of the students who did and did not do sport regularly can be seen in Table 1. The relation of branches of sports with Precipitant, Thinking,Avoidant variables that are some of problem-solving approaches can be seen in Table 2. The relation of branches of sports with Assessor, Self-Confident, and Planned variables that are some of problem-solving approaches can be seen in Table 3. For those who did sport regularly $(D(319)=0.119, p=0.000)$ and those who did not do sport regularly $(D(321)=0.102, p=0.000)$, the participants' values for the problem-solving inventory did not have a normal distribution according to the points that they got. According to results of Mann-Whitney U test, a clear difference was not seen among precipitant approach values of athletes and non-athletes $(U=48.7$, $p=0.301, z=-1,035, r=-0.04)$. No important differences were found among thinking approach values of athletes and non-athletes $(U=50.0, p=0.080, z=-0.243, r=-0.00)$. Avoidant approach values of athletes and non-athletes were not separated from each other $(U=48.8, p=0.319, z=-0.997, r=-0.04)$. A significant difference was observed among assessor approach values of athletes and non-athletes (mean=7.94, $s=2.79$ vs. mean $=8.35, s=2.74$, respectively; $U=46.2, p=0.033, z=-2.133, r=-0.08)$. The students who did sport regularly compare emerging results and results thought to have occurred after trying a definite way for solving a problem more often than the students who did not do sport regularly, and they evaluate all ways that they can use for solving the problem. A significant difference was observed among self-confident approach values of athletes and non-athletes (mean $=11.22, s=3.98$ vs. mean $=11.96, s=4.05$, respectively; $U=45.0, p=0.008, z=-2.636, r=-0.10)$. The students who did sport regularly believed in themselves that the problems could be solved more effectively and creatively while solving a problem more often than the students who did not do sport regularly, and they followed more systematic way while solving a problem. No significant difference was observed among planned approach values of athletes and non-athletes $(U=47.5, p=0.117, z=-1.567, r=-0.06)$. When the effect of the student-athletes' branches of sport on problem-solving approaches was examined via Kruskal-Wallis one-way analysis, the difference of branches of sport had no effect on problem-solving approaches $(H=4.757, S D=10, p=0.907)$. In other words, branches of sports of student-athletes did not cause any difference in their problem-solving approaches.

Table 1. Mann-Whitney U Analysis of Variance of PSI Scores of Athletes and Non-Athletes

\begin{tabular}{ccccccc}
\hline \multirow{2}{*}{ PSI Variance } & \multicolumn{2}{c}{ Athlete n=319 } & \multicolumn{7}{c}{ Non-athlete $\mathbf{n = 3 2 1}$} \\
\cline { 2 - 7 } & \multicolumn{1}{c}{$\boldsymbol{M}$} & $\boldsymbol{S} \boldsymbol{D}$ & $\boldsymbol{M}$ & $\boldsymbol{S}$ & $\boldsymbol{Z}$ & $\boldsymbol{p}$ \\
\hline Precipitant Approach & 28.84 & 5.98 & 29.18 & 6.15 & -1.035 & .30 \\
Thinking Approach & 12.05 & 4.05 & 12.14 & 4.13 & -.243 & .80 \\
Avoidant Approach & 10.46 & 3.91 & 10.82 & 4.34 & -.997 & .31 \\
Assessor Approach & 7.94 & 2.79 & 8.35 & 2.74 & -2.133 & $.03^{*}$ \\
Self-Confident & 11.22 & 3.98 & 11.96 & 4.05 & -2.636 & $.00^{*}$ \\
Approach & 9.26 & 2.58 & 9.57 & 2.82 & -1.567 & .11 \\
Planned Approach & $\mathbf{7 9 . 7 8}$ & $\mathbf{1 6 . 9 3}$ & $\mathbf{8 2 . 4 2}$ & $\mathbf{1 7 . 0 4}$ & $\mathbf{- 2 . 2 9 5}$ & $\mathbf{. 0 2}^{*}$ \\
\hline Total & & & & & &
\end{tabular}

$p<0.05$

Source: own study. 
Table 2. Kruskal-Wallis Analysis of Precipitant, Thinking, Avoidant PSI Samples of Branches of Sport

\begin{tabular}{|c|c|c|c|c|c|c|c|c|c|c|c|c|c|}
\hline \multirow{2}{*}{ Sports } & \multicolumn{5}{|c|}{ Precipitant } & \multicolumn{4}{|c|}{ Thinking } & \multicolumn{4}{|c|}{ Avoidant } \\
\hline & $N$ & $M$ & $S D$ & $H$ & $p$ & $M$ & $S D$ & $H$ & $p$ & $M$ & $S D$ & $\boldsymbol{H}$ & $p$ \\
\hline Track \& Field & 88 & 28.65 & 5.61 & & & 12.38 & 4.24 & & & 10.29 & 3.58 & & \\
\hline Cross-Country & 12 & 30.00 & 7.76 & & & 11.08 & 3.14 & & & 9.33 & 3.77 & & \\
\hline Running & 32 & 27.81 & 5.05 & & & 12.65 & 3.51 & & & 10.34 & 3.05 & & \\
\hline Shooting & 22 & 28.04 & 7.08 & & & 10.95 & 4.71 & & & 11.22 & 4.50 & & \\
\hline Tennis & 19 & 28.00 & 4.84 & & & 12.94 & 3.82 & & & 9.84 & 3.76 & & \\
\hline Table Tennis & 11 & 29.90 & 4.70 & & & 12.54 & 3.44 & & & 9.63 & 2.76 & & \\
\hline Taekwondo & 29 & 30.03 & 8.16 & & & 11.37 & 3.89 & & & 11.20 & 5.27 & & \\
\hline Folk Dance & 37 & 29.27 & 5.66 & & & 11.59 & 4.32 & & & 10.05 & 3.40 & & \\
\hline Basketball & 29 & 29.75 & 5.27 & & & 12.68 & 3.72 & & & 11.82 & 4.59 & & \\
\hline Handball & 22 & 29.36 & 7.21 & & & 11.31 & 4.83 & & & 10.04 & 4.73 & & \\
\hline Volleyball & 15 & 26.86 & 4.45 & & & 12.60 & 3.58 & & & 10.26 & 2.98 & & \\
\hline Total & 319 & 28.84 & 5.98 & 4.75 & .90 & 12.05 & 4.05 & 11.38 & .32 & 10.46 & 3.91 & 5.97 & .81 \\
\hline
\end{tabular}

Source: own study.

Table 3. Kruskal-Wallis Analysis of Assessor, Self-Confident, Planned PSI Samples of Branches of Sport

\begin{tabular}{|c|c|c|c|c|c|c|c|c|c|c|c|c|c|}
\hline \multirow{2}{*}{ Sports } & \multirow[b]{2}{*}{$N$} & \multicolumn{4}{|c|}{ Assessor } & \multicolumn{4}{|c|}{ Self-Confident } & \multicolumn{4}{|c|}{ Planned } \\
\hline & & $M$ & $S D$ & $\boldsymbol{H}$ & $p$ & $M$ & $S D$ & $H$ & $p$ & $M$ & $S D$ & $\boldsymbol{H}$ & $p$ \\
\hline Track \& Field & 88 & 7.89 & 2.87 & & & 11.47 & 4.09 & & & 9.36 & 2.59 & & \\
\hline Cross-Country & 12 & 8.66 & 1.43 & & & 10.50 & 3.37 & & & 9.00 & 1.90 & & \\
\hline Running & 32 & 7.65 & 2.77 & & & 11.59 & 4.11 & & & 10.03 & 2.75 & & \\
\hline Shooting & 22 & 8.00 & 3.25 & & & 9.86 & 3.07 & & & 8.96 & 2.80 & & \\
\hline Tennis & 19 & 7.52 & 2.61 & & & 12.89 & 4.61 & & & 9.89 & 2.72 & & \\
\hline Table Tennis & 11 & 8.90 & 2.66 & & & 10.36 & 3.26 & & & 9.27 & 2.24 & & \\
\hline Taekwondo & 29 & 7.86 & 2.74 & & & 11.75 & 3.29 & & & 8.86 & 2.11 & & \\
\hline Folk Dance & 37 & 7.78 & 2.88 & & & 10.70 & 4.48 & & & 8.81 & 2.70 & & \\
\hline Basketball & 29 & 8.31 & 2.85 & & & 11.44 & 4.24 & & & 9.34 & 2.59 & & \\
\hline Handball & 22 & 7.90 & 3.29 & & & 10.27 & 3.94 & & & 8.22 & 2.54 & & \\
\hline Volleyball & 15 & 7.66 & 2.19 & & & 11.86 & 3.29 & & & 10.06 & 2.78 & & \\
\hline Total & 319 & 7.94 & 2.79 & 6.06 & .81 & 11.22 & 3.98 & 10.27 & .41 & 9.26 & 2.58 & 10.52 & .39 \\
\hline
\end{tabular}

Source: own study.

\section{Discussion}

According to the results obtained, when the students who exercise regularly encounter a problem, they compare emerging results and results thought to have occurred after trying a definite way for solving a problem more often than the students who are not athletes. They evaluate all ways that they can use for solving the problem, and they also include their emotions in problem-solving process. Further, when studentathletes encounter a problem, they believe that they have the capacity for solving new and difficult problems that will be caused by the situation effectively and creatively and that they will solve the problem more than non-athlete students do. One thing that makes student-athletes different is that they prefer reaching a conclusion more often via a systematic method while solving the problem and making a decision. Studentathletes are pleased with decisions that they make during problem-solving process because of the fact that they believe in themselves too much. Student-athletes have to cope with some different situations according to their branch of sport more than the non-athlete students do. For the great majority of people who do sports, performing well in difficult, challenging, or highly emotional circumstances, e.g., competitive situations, is a problem. Elite athletes can control their anxiety at important times within their performance. Further, the anxiety perception of people who do sports is also crucial (Wesson, Wiggins-James, Thompson, \& Hartigan, 2005). For student-athletes, each competition brings new questions and problems with it. This situation normally causes stress in the athlete. This stress should be managed in a controlled manner. Teachers and trainers should decrease problems and factors constituting stress to be able to manage the stress and bring excitement under control (Wesson et al., 2005). All the difficulties that student-athletes had, their struggle against these difficulties, and their continuous and determined attitudes in solving the problems provide them 
some advantages over the students who do not have these difficulties and do not exercise regularly in school teams. The results of this study support that when the students who do sport regularly encounter a problem, they display more efficient problem-solving approaches than the students who are not athletes and are of the same age. Especially, behaviors of the students who did sport regularly were at more significant level and positive than the students who did not do sport because they believed in themselves while solving the problem. Similarly, the students who did sport regularly showed considerably more positive behaviors about evaluating the results that were obtained after solving the problem than those who did not do sport and were of the same age. Acar, Akandere, and Bastug (2013) stated that football exercises (regular football training) applied in this study positively affect problem-solving skills of children ( $12 \pm 08$ years). It was stated in the studies that were carried out that positive personality characteristics of individuals, such as a sense of selfconfidence, being brash, being active and assertive, being able to think creatively, autonomy, leadership, and courage, have a positive impact on problem-solving skills (Clark, 2002; Gaffrey, 1987; Grawitch et al., 2003; Greenberger et al., 1991; Karabulut, \& Kuru, 2009). Exercise can be used as a tool for encouraging physical self-esteem and other important physical self-perceptions such as body image. This development is accompanied by enhanced self-respect in some situations (Biddle et al., 2002). It was stated in a study carried out with Greek athletes that elite athletes have skills to cope with difficulties more efficiently than athletes who are not elite (Weinberg and Gould, 2003). Erozkan (2013) came to conclusion that having effective problem-solving skills improved communication skills. It was also thought that efficient problem solvers use much behavior to be successful in an academic environment, and in relation to that, it was seen that intrinsic feelings and behaviors such as problem-solving capacity, social assistance, and self-confidence are also generally related to intellectual successes such as sport and art (Elliott, Godshall, Shrout, \& Witty, 1990). Baumann (1994) stated that attention should be paid to creative thinking in physical education lessons and especially in gymnastics lessons. Baumann also states that the students reveal their aesthetic characteristics and creativity in physical education lessons. The movements that are repeated continuously become autonomous in time. Benson (1995) emphasized that problem solving is an intellectual skill that can be learnt and developed with experiences. It can be said that the activities that are repeated continuously in physical education lessons develop skills and creativity characteristics and that this situation helps their problem-solving skills. It was stated in a study carried out the role of nonlinear pedagogy in explaining and facilitating creative behaviors within the sport performance context that creative athlete-environment interaction is based on an athlete's self-experimentation with constraint configurations (Hristovski, David, Passos, \& Araújo, 2012). For any set of interacting constraints, a movement emerges spontaneously. It follows that a novel athlete-environmental interaction is predicated on a novel constellation of constraints that athlete discovers by experimentation. Moreover, in team sports, it is very important to realize that under the confluence of constraints such as the inter-individual distance and relative speed of athletes, a special critical region is formed, characterized by a high level of possible action solutions, each of which is idiosyncratic and formed by specific set of interacting constraints. In the study carried out by Wright, Macdonald, and Burrows (2004), it was stated that physical education will also contribute to the wider educational goals of providing opportunities for students to learn how to engage with knowledge-that is, that physical education will engage students in activities that require critical thinking, critical inquiry, problem solving, and collaboration with others in the process of learning. Weinberg and Gould (2003) stated that exercise and increased level of fitness appear to be associated with increases in self-esteem, especially among individuals initially low in self-esteem. In the Unites States, a physical activity program of at least 20 minutes was applied to elementary school students in breaks; this physical activity that was provided to students ensured that the students had a healthy body and that they spent their time by having fun. Sozen (2012) stated that high school physical education and sports training had positive effects on problem-solving skills of athletes. His study found that avoiding, thinking, estimator, self-trust, and planned approach skills are statistically higher in the athletes studying in the school of physical education and sports. Further, it also allows children to have the opportunity to practice life skills such as cooperation, taking turns, following rules, sharing, communication, negotiation, problem solving, and conflict resolution (National Association for Sport and Physical Education, 2006). Researchers found that college academic support programs 
are most successful when they address not only students' academic needs but also their social and cultural needs (Natt Gantt, 2012). Our study findings revealed that high school students who do sport regularly believe in themselves while solving a problem more than those who do not do sport regularly and that they evaluate occurring situations more efficiently after the problem is solved, and thus it can be said that regular physical activity should be absolutely be included in the said programs while preparing an academic education program. Similarly, it was determined in the study carried out by Sagir (2011) among teachers that physical education teachers get minimum points from PSI compared to other branch teachers and that they have more efficient problem-solving skills.

In another study, Pehlivan and Konukman (2010) stated that although there was no significant difference among physical education teachers and other teachers for detecting problem-solving skills, the points that physical education teachers got showed that they have more efficient problem-solving behaviors. In study findings, no significant difference could be found between the PSI scores of athletes performing different branches of sport. In similar studies, no significant difference was found in problemsolving approach in comparing branches of sport. In her study Gulsen (2008) analyzed problem-solving skills of footballers, their league level, positions, and sport age variables, and did not encounter any significant difference statistically. Bezci (2010) analyzed problem-solving skills of taekwondo coaches; he stated that there were no significant differences in the problem-solving skills of taekwondo coaches, with respect to coaching degree, years of coaching, actively coaching, education, education of parents, PES education status, family's socioeconomic status, or behavior of parents. On the other hand, problem-solving skills of coaches differed in terms of birth order and gender.

The fact that student-athletes believe in themselves while solving problems, think systematically, and evaluate occurring results shows that they positively control the pressure environment caused by the problem and stress. Studies have clearly and consistently shown that a period of exercise training can reduce trait anxiety (Biddle et al., 2002). Physical activity is consistently associated with positive affect and mood (Biddle et al., 2002). Sport participants who can defeat anxiety and focus on the task while they are controlling their physiological arousal responses will be more pleasant and perform better than those who cannot adjust or control their anxiety (Gill, 1986).

Trainers prepare their athletes via training programs planned by them for the difficulties that athletes will encounter during performance (Wesson et al., 2005). Unexpected situations cause that negative anxiety occurs on athletes. Stress and anxiety continuously experienced by athletes during trainings cause the athlete to have solutions for the problem earlier. Further, athletes react to stressful situations in a more controlled way and solve the situation causing the problem more determinedly. Exercise training appears to have the greatest trait anxiety-reducing effects when the duration is at least 10 weeks, with the greatest benefits over 15 weeks (Biddle et al., 2002). Further, exercise training has been successfully used to reduce trait anxiety in a wide range of clinical and nonclinical settings (Biddle et al., 2002).

It is very clear that regular training has many physical and physiological gains. Adolescents are increasingly likely to develop lifelong habits of physical activity if they perceive sport participation as useful for their physical fitness, as a way to maintain or improve skills, and as a means to improve appearance, muscular strength, endurance, and flexibility (Pateli, \& Greydanus, 2010). However, psychological and social gains of regular sportive activities increase still more the importance of fast presentday living conditions. According to results of the study, it can be said that student-athletes who do regular sport and exercise at high schools are more effective problem solvers than the students who are not athletes and are in the same age group. Within this scope, the fact that a time frame in which the students can exercise regularly is constituted in high school curricula and that the students exercise regularly within a program will contribute positively to their problem-solving skills. Further, when students exercise regularly as a member of sport teams during out-of-school times, they will be more effective problem solvers against the difficulties that they will encounter in their social lives. If similar studies are applied to secondary and university students and they exercise regularly before and after adolescence, this will be beneficial to evaluate its effects on problem solving. 


\section{REFERENCES}

Acar, K., Akandere, M., \& Bastug, G. (2013). A study of problem solving skills and non-functional attitudes of children who get training for football. Turkish Journal of Sport and Exercise, 15(3), 69-74.

Arnold, P. J. (1997). Sport, Ethics and Education. London, England: Cassell.

Baumann, S. (1994). Praxis der Sportpsychologie (C. Ikizler, \& A. Ozcan, Trans.). Istanbul, Turkey: Alfa.

Benson, A. (1995). Problem-solving skills training. Habilitative Mental Healthcare Newsletter, 14(1).

Bezci, S. (2010). The Study of Relationship Between Coping Style with Stress and Problem Solving Skills of Taekwondo Coaches. Unpublished doctoral dissertation, University of Gazi, Ankara.

Biddle, S.J.H., Kenneth, R.F., \& Boutcher, S.H. (2002). Physical Activity and Psychological Well-being. London, England: Routledge-Taylor \& Francis.

Bingham, A. (1958). Improving Children's Facility in Problem Solving (A.F. Oguzkan, Trans.). New York, NY: Bureau of Publications, Teachers College, Columbia University.

Blumenstein, B., \& Orbach, I. (2012). Psychological Skills in Sport:Training and Application. Happauge, NY: Nova Science.

Cox, R.H. (1998). Sport Psychology: Concepts and Applications. Boston: McGraw-Hill.

Clark, C.J. (2002). Problem Solving and Personality Factors of Two At-risk College Populations. Unpublished doctoral dissertation, University of West Virginia.

Davis, B., Roscoe, J., Roscoe, D., \& Bull, R. (2005). Physical Education and the Study of Sport. New York, NY: Elsevier Mosby.

D'Zurilla T.J., \& Nezu, M. (1990). Development and preliminary evaluation of the social problem solving: Psychological assessment: A Journal of Consulting and Clinical Psychology, 2(2), 156-163.

D'Zurilla, T.J, Nezu, A.M., \& Nezu, C.M. (2007). Solving Life's Problems: A 5-step Guide to Enhanced Well-being. New York, NY: Springer.

Erozkan, A. (2013). The effect of communication skills and interpersonal problem solving skills on social self-efficacy educational sciences. Theory \& Practice, Educational Consultancy and Research Center.Retrieved from www.edam.com.tr/estp, 13(2), 739-745.

Elliott, T.R., Godshall, J., Shrout, E., \& Witty, T. (1990). Problem solving appraisal, self-reported study habits and performance of academically risk. College Students. Journal of Counseling Psychology, 37(2), 203-207.

Ferah, D. (2000). Investigation of Perception of Problem Solving Skills and Problem Solving Approaches of the Turkish Army Academy Cadets in Terms of Gender, Grade, Academic Success and Leadership. Unpublished doctoral dissertation, University of Hacettepe, Ankara.

Gaffrey, J.B. (1987). Problem-solving in Small Groups of Type A's and Type B's. Unpublished doctoral dissertation, University of South Carolina, South Carolina.

Gill, D.L. (1986). Psychological Dynamics of Sport. Champaign, IL: Human Kinetics Publishers.

Grawitch, M.J., Munz, D.C., \& Eliot, E.K. (2003). Promoting creativity in temporary problem-solving groups: The effect of positive mood and autonomy in problem solving definition on idea generating performance. Group DynamicsTheory Research and Practice, 7(3), 200-213.

Greenberger, E., O’Connor, J., \& Sorensen, A. (1991). Personality, cognitive and academic correlates of problem solving flexibility. Developmental Psychology, 4(3), 416-424.

Gulsen, D. (2008). Analyzing the Players Who are Playing in Different Division Levels, the Problem Solving Abilities of the Soccer Players According to League, Education Levels and Sport Age. Unpublished master's thesis, University of Cukurova, Adana.

Hagger, M., \& Chatzisarantis, N. (2005). Social Psychology of Exercise and Sport. Boston: McGraw-Hill Professional. Heppner, P.P., \& Petersen, C.H. (1982). The development and implications of a personal problem-solving inventory. Journal of Counseling Psychology, 15(1), 66-75.

Hristovski, R., Davids, K., Passos, P., \& Araújo, D. (2012). Sport performance as a domain of creative problem solving for self-organizing performer-environment systems. Open Sports Sciences Journal, 5(Suppl. 1-M4), 26-35. 
Karabulut, E., \& Kuru, E. (2009). Review of several variables of characteristics of the students in physical education and sport department of Ahi Evran University and the ability of problem solving. Education Faculty Journal of Ahi Evran University, 10(3), 119-127.

Mellalieu, S.D., Hanton, S., \& Fletcher, D. (2009). A Competitive Anxiety Review: Recent Directions in Sport Psychology Research. New York, NY: Nova Science.

National Association for Sport and Physical Education (2006, May). Recess for Elementary School Students /Position paper/. Reston, VA: Author.

Natt Gantt, Larry O., II. (2012). Pedagogy of problem solving: Applying cognitive science to teaching legal problem solving. Creighton Law Review, 45, 699-762.

Patel, D.R., Greydanus, D.E., Omar, H.A., \& Merrick, J. (Eds.) (2010), Health and Human Development: Adolescence and Sports. New York, NY: Nova Science.

Pehlivan, Z., \& Konukman, F. (2004). Comparing the physical education teachers and the other branch teachers in the aspect of problem solving. Spormetre, Physical Education and Sport Science Journal, 2(2), 55-60.

Sahin, N., \& Heppner, P.P. (1993). Psychometric properties of the problem solving inventory in a group of Turkish university students. Cognitive Therapy and Research, 17(4), 379-396.

Sozen, H. (2012). The effect of physical education and sports school training on problem solving skills of the athletes. Procedia - Social and Behavioral Sciences, 46, 4186-4190.

Thornton, S. (1998). Children Solving Problems (O. Kumrular, Trans.). Cambridge, MA: Harvard University Press.

Ulucinar, S. (2011). Research on problem solving skills of teacher candidate. E-Journal of New World Sciences Academy Education Sciences, 1C0455, 6(4), 2482-2494.

Weinberg, R.S., \& Gould, D. (2003). Foundations of Sport and Exercise Psychology. Champaign, IL: Human Kinetics.

Wesson, K., Wiggins-James, N., Thompson, G., \& Hartigan, S. (2005). Sport and PE: A Complete Guide to Advanced Level Study (3rd ed.). London, England: Hodder \& Stoughton Education.

Woods, B. (2004). Applying Psychology to Sport. London, England: Hodder \& Stoughton Education.

Wright, J., Macdonald, D., \& Burrows, L. (2004). Critical Inquiry and Problem-solving in Physical Education. London, England: Routledge.

AUTHOR'S ADDRESS: $\quad$ Fatih Senduran

Gülhane Military Medical Academy

Etlik/Ankara, 06100, Turkey

Email: fsenduran@yahoo.com

Received: 16 June 2014; Accepted: 28 August 2015 